\title{
DISTRATOS NO MERCADO IMOBILIÁRIO: CRÍTICAS AO MODELO SOLIDARISTA DE CONTRATO E A ANÁLISE ECONÔMICA DO DIREITO CONTRATUAL
}

\author{
DISTRACTS IN THE REAL ESTATE MARKET: CRITICISM OF THE SOLIDARIST \\ CONTRACT MODEL AND THE ECONOMIC ANALYSIS OF CONTRACTUAL LAW
}

Fernando Gustavo Knoerr ${ }^{1}$ Henrique Ribeiro Cardoso ${ }^{2}$

Fernando Virmond Portela Giovannetti ${ }^{3}$

\section{RESUMO}

A grave crise econômica que teve início no ano de 2015 atingiu de forma substancial o mercado imobiliário brasileiro. Um dos sintomas da crise no setor, bem como uma das consequências, como num círculo vicioso, consistiu no aumento expressivo de inadimplência por parte de compradores de imóveis adquiridos na planta, o que se agravou com a consolidação de uma jurisprudência paternalista adotada pelo STJ em benefício dos consumidores. No presente artigo, pretende-se identificar problemas no modelo solidarista de contrato, predominante na doutrina e

\footnotetext{
${ }^{1}$ Realizou estágio Pós- Doutoral na Universidade de Coimbra, Portugal. Doutor e Mestre em Direito do Estado Professor de Direito Administrativo da Escola da Magistratura do Paraná e da Fundação Escola do Ministério Público do Paraná / FEMPAR. É Professor Permanente do Programa de Mestrado em Direito Empresarial e Cidadania do UNICURITIBA. Ex-Procurador Federal. Ex-Juiz do TRE/PR. Advogado Sênior do Escritório Séllos-Knoerr Sociedade de Advogados.

${ }^{2}$ Doutor em Direito, Estado e Cidadania (UGF/Rio), com Pós-doutorado em Democracia e Direitos Humanos (IGC - Universidade de Coimbra) e Pós-doutorado em Direitos Humanos e Desenvolvimento (PPGCJ/UFPB); Mestre em Direito, Estado e Cidadania (UGF/Rio); Especialista em Direito Constitucional Processual (FAPESE/UFS); Graduado em Direito pela Universidade Estadual de Santa Cruz (UESC/Bahia); Professor do Programa de Pós-graduação da Universidade Federal de Sergipe (Mestrado/PRODIR/UFS); Professor de Programa de Pós-graduação da Universidade Tiradentes (Mestrado/PPGD/UNIT); Professor da Escola Superior do Ministério Público de Sergipe (ESMP/SE); Membro da Academia Sergipana de Letras Jurídicas (ASLJ/SE) e Líder do Grupo de Pesquisa Constitucionalismo, Cidadania e Concretização de Políticas Públicas e Promotor de Justiça em Sergipe.

${ }_{3}^{3}$ Mestrando em Direito Empresarial e Cidadania pelo UNICURITIBA. Graduado em Direito pela Faculdade de Direito da Universidade Federal do Paraná.
} 
na jurisprudência pátrias, e apontar para possíveis soluções baseadas no instrumental fornecido pela Análise Econômica do Direito.

PALAVRAS-CHAVE: Distrato; Função social do contrato; Análise econômica do direito.

\section{ABSTRACT}

The severe economic crisis that began in 2015 has substantially affected the Brazilian real estate market. One of the symptoms of the crisis in the sector, as well as one of the consequences, as in a vicious circle, was the significant increase of default by buyers of properties acquired in the plant, which was aggravated by the consolidation of a paternalistic jurisprudence adopted by the STJ in benefit ratio of consumers. In this article, we intend to identify problems in the jointly liable model of contract, predominant in doctrine and jurisprudence of the country, and to point out possible solutions based on the instruments provided by the Economic Analysis of Law.

KEYWORDS: Distract; Social function of contract; Economic analysis of law.

\section{INTRODUÇÃO}

Até meados de 2014, o mercado imobiliário brasileiro experimentava seus melhores momentos, com expressiva valorização do metro quadrado e crescimento significativo de novos empreendimentos. Fazia parte do imaginário popular, do senso comum, a ideia da aquisição do imóvel não apenas como a realização do "sonho da casa própria”, mas também a de um investimento com retorno substancial e garantido. 
De superaquecido, o setor imobiliário passou a enfrentar os seus piores dias com o advento da crise política e econômica em 2015 - que perdura até hoje. Consumidores perderam o emprego, investidores viram o preço do metro quadrado despencar, o aumento da taxa de juros resultou num incremento relevante no valor das parcelas dos financiamentos imobiliários; o cenário de crise, em suma, se alastrou para quase todos os setores da economia - em particular para o mercado imobiliário.

Uma das questões mais sintomáticas desse quadro de crise no setor imobiliário, tanto sob a ótica das construtoras e incorporadoras quanto a dos consumidores, é o sensível aumento dos distratos em contratos de compromisso de compra e venda de imóveis na planta. Para se ter noção da gravidade da crise, entre os meses de fevereiro de 2016 e de $2017,57,9 \%$ dos contratos de compromisso de compra e venda de imóveis de alto e médio padrão adquiridos na planta na cidade de São Paulo foram cancelados ${ }^{4}$.

De acordo com a matéria jornalística veiculada no portal de notícias UOL, em fevereiro de 2017, o grupo PDG, então uma das maiores incorporadoras do Brasil (que, em 2012, chegou a ter valor de mercado equivalente a $\mathrm{R} \$ 12$ bilhões de reais), ingressou na justiça com pedido de recuperação judicial ${ }^{5}$. Segundo a matéria, um dos fatores mais decisivos para o pedido de recuperação judicial pelo grupo PDG foi justamente o aumento relevante da quantidade de distratos dos imóveis vendidos na planta.

\section{TRATAMENTO LEGAL E JURISPRUDENCIAL SOBRE OS DISTRATOS}

Mesmo antes do início da crise, eram comuns os questionamentos nos Tribunais sobre a possibilidade de estipulação nos contratos de promessa de compra e venda de cláusula de decaimento, ou seja, de cláusula que estabelecia a perda integral das parcelas já pagas pelo adquirente em caso de inadimplemento.

\footnotetext{
4 GARCIA, Alexandre. Metade dos imóveis vendidos volta à construtora devido aos distratos. Disponível em: <>. Acesso em 16/01/2018.

$5 \quad$ AGOSTINI, Renata. Pdg tem novo prejuízo bilionário e caminha para recuperação judicial. Disponível em: <>. Acesso em 16/01/2018.
} 
A lei $n^{\circ} 4.594 / 1964$, que rege os condomínios edilícios e a incorporação imobiliária, trata do contrato de compra e venda de imóveis na planta no $\S 2^{\circ}$ do artigo 34 da seguinte forma:

Art. 34 .

$[\ldots]$

$\S 2^{\circ}$. Os contratos de compra e venda, promessa de venda, cessão ou promessa de cessão de unidades autônomas são irretratáveis e, uma vez registrados, conferem direito real oponível a terceiros, atribuindo direito a adjudicação compulsória perante o incorporador ou a quem o suceder, inclusive na hipótese de insolvência posterior ao término da obra (Lei $\mathrm{n}^{\circ}$ 4.594, de 16 de dezembro de 1964).

Pela leitura do dispositivo supra transcrito, os contratos de compra e venda de unidades autônomas são irretratáveis e irrevogáveis. Logo, a cláusula de decaimento prevista nos contratos de promessa de compra e venda teria amparo legal.

Entretanto, o Código de Defesa do Consumidor prevê a nulidade de cláusulas de decaimento, senão vejamos:

\begin{abstract}
Art. 53. Nos contratos de compra e venda de móveis ou imóveis mediante pagamento em prestações, bem como nas alienações fiduciárias em garantia, consideram-se nulas de pleno direito as cláusulas que estabeleçam a perda total das prestações pagas em benefício do credor que, em razão do inadimplemento, pleitear a resolução do contrato e a retomada do produto alienado (Lei $n^{\circ} 8078$, de 11 de setembro de 1990).
\end{abstract}

Antes mesmo do setor imobiliário entrar na profunda crise que ainda perdura, Tribunais de todo o país, e em particular o STJ, passaram a enfrentar as questões acerca da abusividade das cláusulas de decaimento frequentemente previstas em contratos de compromisso de compra e venda de imóveis adquiridos na planta.

De acordo com a já pacificada jurisprudência do STJ, é abusiva a cláusula de decaimento nos contratos de promessa de compra e venda quando submetidos à legislação consumerista, justamente por conta da proibição expressa do art. 53 do Código de Defesa do Consumidor. O STJ tem admitido apenas a previsão de multa 
contratual compensatória entre $10 \%$ e $25 \%$ sobre o valor das parcelas já pagas pelo adquirente-consumidor ${ }^{6}$.

No ano de 2015, o STJ editou uma Súmula de sua jurisprudência com o seguinte teor, tentando pacificar definitivamente a matéria:

Súmula 543-STJ: Na hipótese de resolução de contrato de promessa de compra e venda de imóvel submetido ao Código de Defesa do Consumidor, deve ocorrer a imediata restituição das parcelas pagas pelo promitente comprador - integralmente, em caso de culpa exclusiva do promitente vendedor/construtor, ou parcialmente, caso tenha sido o comprador quem deu causa ao desfazimento. (STJ. $2^{\text {a }}$ Seção. Aprovada em 26/8/2015, DJe $31 / 8 / 2015)$

\section{REFLEXÕES CRÍTICAS À SÚMULA 543 DO STJ}

Longe de solucionar o problema real, tanto das construtoras e incorporadoras quanto da coletividade de consumidores, a pacificação da matéria através da edição da Súmula $n^{\circ} 543$ da jurisprudência do STJ é apenas aparente, porquanto confere tratamento idêntico a casos concretos bastante diversos, dando ensejo a situações

$6 \quad$ Nesse sentido: "DIREITO CIVIL. RECURSO ESPECIAL. CONTRATO DE COMPRA E VENDA DE IMÓVEL. DISTRATO. DEVOLUÇÃO ÍNFIMA DO VALOR ADIMPLIDO. ABUSIVIDADE. RETENÇÃO DE PERCENTUAL SOBRE O VALOR PAGO. SÚMULA 7 DO STJ. 1. "O distrato faz-se pela mesma forma exigida para o contrato" (art. 472 do Código Civil), o que significa que a resilição bilateral nada mais é que um novo contrato, cujo teor é, simultaneamente, igual e oposto ao do contrato primitivo. Assim, o fato de que o distrato pressupõe um contrato anterior não lhe desfigura a natureza contratual, cuja característica principal é a convergência de vontades. Por isso, não parece razoável a contraposição no sentido de que somente disposições contratuais são passíveis de anulação em virtude de sua abusividade, uma vez que "'onde existe a mesma razão fundamental, prevalece a mesma regra de Direito". 2. A lei consumerista coíbe a cláusula de decaimento que determine a retenção do valor integral ou substancial das prestações pagas por consubstanciar vantagem exagerada do incorporador.3. Não obstante, é justo e razoável admitir-se a retenção, pelo vendedor, de parte das prestações pagas como forma de indenizá-lo pelos prejuízos suportados, notadamente as despesas administrativas realizadas com a divulgação, comercializacão e corretagem, além do pagamento de tributos e taxas incidentes sobre o imóvel, e a eventual utilizacão do bem pelo comprador. 4. No caso, o Tribunal a quo concluiu, de forma escorreita, que o distrato deve render ao promitente comprador 0 direito à percepcão das parcelas pagas. Outrossim, examinando o contexto fático-probatório dos autos, entendeu que a retenção de $15 \%$ sobre o valor devido seria suficiente para indenizar a construtora pelos prejuízos oriundos da resilição contratual. Incidência da Súmula 7 do STJ. 5. Recurso especial não provido".(grifos nossos) (STJ, REsp 1.132.943/PE, 4. ${ }^{a}$ T., j. 27.08.2013, rel. Luis Felipe Salomão, D. 27.09.2013). 
injustas e a encargos desproporcionais para os empreendimentos imobiliários e, reflexamente, para outros adquirentes das unidades imobiliárias.

Especificamente sobre as decisões judiciais que adotam tal entendimento, Arnaldo Rizzardo pondera que

\begin{abstract}
essa abertura constitui precedente perigoso, em se tratando de incorporação, pelas consequências que traz, como a viabilidade de desestruturar todo um planejamento, inviabilizando o seguimento da construção. Terceiros adquirentes serão atingidos e prejudicados, dado o agravamento dos encargos, porquanto deverão assumir os encargos, no regime da incorporação por empreitada ou administração. Se o negócio foi com o incorporador, possível que repercuta a desistência no orçamento, vindo a desfalcá-lo de importância que mantinha o equilíbrio financeiro. Agrava-se prejuízo com certas decisões que obrigam a restituir, mesmo que admitido o desconto de certo valor. A instabilidade será total com decisões de tal teor, pois viabiliza a generalização de desistências ${ }^{7}$.
\end{abstract}

Cumpre salientar, entretanto, que, com os argumentos trazidos no presente artigo não se pretende anular ou afastar, de forma alguma, a imprescindível proteção ao consumidor conferida pelo CDC e pela própria Constituição da República, nem tampouco os preceitos da função social do contrato, previstos pelo art. 421 do Código Civil, e da boa-fé objetiva.

O que se pretende, na realidade, é trazer à luz uma reflexão sobre a insuficiência da interpretação - e aplicação - isolada do modelo solidarista de contrato, que norteou a jurisprudência do STJ ao proferir diversos julgamentos sobre os distratos e a editar a súmula $\mathrm{n}^{\circ} 543$.

\title{
4. O MODELO SOLIDARISTA DE CONTRATO ${ }^{8}$
}

O modelo tradicional de contrato alçava a autonomia da vontade e a liberdade contratual como dogmas do direito contratual. O contrato consistia, em suma, no autorregramento da vontade das partes, decorrendo daí o princípio de sua força

$7 \quad$ RIZZARDO, Arnaldo. Condomínio Edilício e Incorporação Imobiliária. $5^{\mathrm{a}}$ ed. Rio de Janeiro: Forense, 2017, p.286.

8 TIMM, Luciano Benetti. Direito Contratual Brasileiro: Críticas e Alternativas ao Solidarismo Jurídico. $2^{\mathrm{a}}$ ed. São Paulo: Editora Atlas, 2015. 
obrigatória ${ }^{9}$. Entendia-se que as partes eram livres para contratar e para preencher todo o conteúdo do contrato, não cabendo ao Estado promover qualquer tipo de ingerência no que então havia sido tratado pelos contratantes (exceto sobre os vícios de consentimento, a capacidade contratual, a licitude do objeto).

Com a promulgação da Constituição de 1988, com a edição do Código de Defesa do Consumidor em 1990 e com a edição do Código Civil de 2002, o modelo tradicional e individualista de contrato foi superado, dando lugar ao modelo solidarista ou social de contrato.

Essa mudança do modelo de contrato decorreu de diversos fatores. De um lado, o mundo contemporâneo tornou-se mais complexo, posto que as relações contratuais passaram a ser massificadas, despersonalizadas, homogêneas, prevalecendo a contratação por adesão. De outro, o próprio Direito sofreu profundas alterações com a emergência do Estado Social, dando ensejo ao fenômeno da constitucionalização do direito privado, da prevalência da igualdade material sobre a igualdade formal, da proteção dos grupos vulneráveis. A boa-fé e a função social dos contratos tornaramse pedra angular do direito privado contemporâneo ${ }^{10}$.

A insigne jurista consumerista Cláudia Lima Marques destaca que

À procura do equilíbrio contratual, na sociedade de consumo moderna, o direito destacará o papel da lei como limitadora e como verdadeira legitimadora da autonomia da vontade. A lei passará a proteger determinados interesses sociais, valorizando a confiança depositada no vínculo, as expectativas e a boa-fé das partes contratantes. ${ }^{11}$

9 MARQUES, Cláudia Lima. Contratos no Código de Defesa do Consumidor: o novo regime das relações contratuais. $8^{\text {a }}$ Ed. São Paulo: Editora Revista dos Tribunais, 2016, p. 62-71.

10 Nesse sentido, a insigne jurista Cláudia Lima Marques ensina que "Outro ponto a destacar, além da importância dos paradigmas sociais no direito das obrigações em geral. Com a entrada em vigor do Código Civil de 2002, o paradigma máximo da boa-fé, que caracterizava o modelo contratual do CDC e guiava esta exposição, generalizou-se para todos os contratos no direito privado brasileiro (arts. 113, 187 e 422 do CC/2002), seja um contrato entre dois iguais, dois civis ou dois empresários, seja entre dois diferentes, um contratante profissional, o fornecedor, e um contratante leigo e vulnerável, o consumidor, logo, este último um contrato de consumo. Parece-me, pois, neste momento de generalização (pois em tempos pós-modernos a generalização geralmente leva à desconstrução), necessário reforçar o paradigma e evitar que se enfraqueça”. Ibid., p. 194/195.

11 MARQUES, 2016, p. 217. 
No modelo solidarista de contrato, a autonomia da vontade e a liberdade contratual não foram anuladas nem se tornaram irrelevantes, mas apenas mitigadas.

A autonomia da vontade deu lugar à "autonomia privada", que preceitua que, ao lado da vontade das partes, no âmbito do contrato, deve-se levar também em conta a existência de normas de ordem pública, o respeito à dignidade humana, a boa-fé objetiva, a função social ${ }^{12}$.

Nas relações contratuais, portanto, são acrescentados elementos não consensuais, exteriores à vontade dos contratantes e previstos no ordenamento jurídico, a fim de corrigir assimetrias e proteger a parte contratante mais fraca, como é o caso dos contratos sob a égide do Código de Defesa do Consumidor.

\subsection{CRÍTICAS AO MODELO SOLIDARISTA DE CONTRATO}

Não há dúvidas de que a mudança do paradigma liberal e individualista para o modelo solidarista do direito contratual representou uma imprescindível evolução para o Direito, mais consentânea com os ditames da Constituição da República de 1988 e com a própria ideia de justiça.

Entretanto, o modelo solidarista não está isento de críticas. Por um lado, este modelo possibilitou a - necessária - abertura do sistema jurídico a elementos axiológicos, aos princípios da eticidade, da função social e da boa-fé objetiva, à preocupação com a justiça distributiva e à proteção das partes mais vulneráveis das relações contratuais.

Por outro lado, a adoção isolada dos ditames solidaristas, tanto pelo Poder Legislativo, na edição de leis, quanto pelo Poder Judiciário, na construção de decisões

\footnotetext{
12 Nesse sentido, de acordo com Flávio Tartuce, "conceitua-se o princípio da autonomia privada como um regramento básico, de ordem particular - mas influenciado por normas de ordem pública, pelo qual na formação do contrato, além da vontade das partes, entram em cena outros fatores: psicológicos, políticos, econômicos e sociais". TARTUCE, Flávio. Direito Civil, v. 3: Teoria Geral dos Contratos e Contratos em Espécie. 11 a ed. Rio de Janeiro: Editora Forense, 2016, p.61.
} 
judiciais, a pretexto de corrigir assimetrias e promover a justiça distributiva, podem provocar consequências indesejáveis e distorções em todo um sistema econômico.

A depender do grau de intervenção estatal nos contratos, ao invés de beneficiar a coletividade e as partes mais vulneráveis da relação, a adoção dos preceitos ditados pelo modelo solidarista pode enrijecer e engessar as relações contratuais, a ponto de ceifar substancialmente a liberdade das partes e mesmo inviabilizar a transação de mercado entre elas. É o que vem ocorrendo, ao menos segundo a interpretação ora adotada, no âmbito do mercado imobiliário diante da jurisprudência dominante sobre os distratos de imóveis adquiridos na planta.

\section{A ANÁlISE ECONÔMICA DO DIREITO E O MODELO CONTRATUAL ECONÔMICO}

Assim como o modelo solidarista, o modelo contratual econômico adota premissas funcionalistas ou consequencialistas ${ }^{13}$. Mas enquanto o modelo solidarista parte de uma ideia paternalista, o modelo contratual econômico adota uma visão individualista ${ }^{14}$.

A Análise Econômica do Direito (AED) pode ser utilizada sob dois prismas diferentes: um, positivo, dirigido à descrição de fatos, das normas jurídicas aplicadas no mundo real, e outro, negativo ou normativo, que se destina à investigação sobre

\footnotetext{
13

"Nesse sentido, a AED é um movimento que se filia ao consequencialismo, isto é, seus praticantes acreditam que as regras às quais nossa sociedade se submete, portanto, o direito, devem ser elaboradas, aplicadas e alteradas de acordo com as consequências no mundo real, e não por julgamentos de valor desprovidos de fundamentos empíricos (deontologismo)". RIBEIRO, Marcia Carla Pereira; AGUSTINHO, Eduardo Oliveira. Economia institucional e nova economia institucional. In: RIBEIRO, Marcia Carla Pereira; KLEIN, Vinicius (Org.). O que é análise econômica do direito: uma introdução. Belo Horizonte: Fórum, 2016, p. 17.

$14 \quad$ Nesse sentido, Luciano Benetti Timm descreve que "A razão para tanto é que o paradigma do Direito e Economia permite a defesa de uma noção antagônica, na comparação com a visão paternalista, do que o contrato é e do que o direito contratual (e a sua função) deve ser, vez que parte do individualismo. Além disso, ambos os movimentos são escolas funcionalistas do pensamento e o problema está em interpretar o que vem a ser a função social do direito contratual". TIMM, op cit., p. 180.
} 
quais seriam as prescrições ou as medidas a serem adotadas para tornar as normas jurídicas mais eficientes ${ }^{15}$.

Sob a primeira perspectiva - a positiva - importa neste artigo a análise das falhas do mercado, que são capazes de afastar o mercado de seu "nível ótimo", tornando-o ineficiente. Dentre as falhas de mercado se destacam as externalidades, as assimetrias de informação e os custos de transação. Para o presente estudo, interessa a análise das externalidades.

Externalidades podem ser conceituadas como efeitos positivos ou negativos gerados em terceiros. No direito ambiental, por exemplo, as externalidades negativas são comumente associadas à poluição provocada por um agente determinado, que acaba por afetar a vida e a saúde de terceiros em decorrência da sua atividade poluidora. O mesmo raciocínio se aplica aos contratos, porquanto, ainda que ele vincule e afete diretamente apenas as partes pactuantes, são capazes de provocar efeitos positivos ou negativos a terceiros estranhos à relação contratual. De acordo com as lições de Luciano Benetti Timm,

\begin{abstract}
O que ocorre nas externalidades é que o excedente econômico dos contratos precisa, para refletir de forma fiel o bem-estar social causado, incluir também a variação na situação de terceiros. Assim, o excedente econômico de contratos que gera externalidades positivas é maior do que as partes normalmente levam em conta. Portanto, um mercado desregulado tende a produzir menos desses contratos do que a quantidade ótima (ou seja, nem todas as transações com excedente positivo são efetuadas). (...) Já o contrário ocorre no caso de contratos com externalidades negativas, visto que o mercado livre tende a produzir mais do que a quantidade ótima desses contratos. Ou seja, nem todas as transações efetuadas terão excedente econômico positivo. Nesses casos, o direito pode exercer um importante papel de internalizar a externalidade, fazendo com que as partes arquem com os custos - no caso das externalidades negativas - ou se beneficiem - nas externalidades positivas - dos efeitos que causam a terceiros. Assim, a quantidade produzida se ajusta automaticamente ao nível eficiente. ${ }^{16}$
\end{abstract}

15 "A AED, em apertada síntese, tem fundamentalmente dois diferentes ângulos de estudo. $O$ positivo - que trabalha com a tentativa de descrição da realidade - e o normativo - que vai além das descrições empíricas e passa a fazer julgamentos prescritivos. A AED positiva, então, esforça-se em mostrar como as normas jurídicas evoluíram de modo a agregar eficiência à sociedade, diminuindo os custos das transações e estimulando as relações econômicas. Já a AED normativa emitirá opiniões sobre a adequação ou não de determinadas regras jurídicas a fins últimos (como aqui se está propondo a sua utilização na leitura da função social do contrato, prevista no art. 421 do Código Civil)". Ibid., p. 178.

$16 \quad$ Ibid., p. 188. 
Já sob o prisma normativo, a AED reafirma os princípios gerais do contrato, como o da autonomia da vontade, do efeito relativo dos contratos, da liberdade de forma, da boa-fé objetiva e, sobretudo, da função social do contrato, este previsto pelo art. 421 do Código Civil.

A AED não é indiferente aos interesses coletivos - e legítimos - dos contratos sobre os quais tanto enfatiza o solidarismo jurídico. Mas o bem-estar social deve ser analisado não somente dentro de uma relação contratual, mas "somente pode ser identificado na estrutura do mercado subjacente ao contrato que está sendo celebrado e ao processo judicial relacionado ao litígio a ele pertinente"17

Significa que a existência e a dinâmica do mercado também devem ser levadas em consideração, tanto pelo Poder Legislativo na edição de leis, quanto pelo Judiciário no exercício da tutela jurisdicional, uma vez que em seu âmbito é exatamente onde os contratos ocorrem. O mercado, em outros termos, é um fato e é parte integrante da sociedade, de sorte que, como outros fatos sociais, podem ser regulados por normas jurídicas.

Sob a perspectiva da AED, bens e direitos devem circular da forma mais livre possível no mercado, de acordo com a vontade das partes expressa no contrato. No geral, se cada uma destas é capaz de estabelecer a própria "escala de preferências, estarão, assim, aptos a maximizar a sua utilidade no processo de transação. Isso gerará riqueza na sociedade" ${ }^{18}$.

A principal função social do direito contratual é a de possibilitar a própria existência de contratos. Sem as regras do direito contratual, as transações simplesmente não ocorreriam, porquanto são justamente elas que protegem os interesses e impõem obrigações legais às partes. Luciano Benetti Timm assevera que 
Inexistindo o direito dos contratos (que cria deveres legais protegidos pelo Estado), as partes teriam dificuldades em estabelecer relações impessoais (fora do círculo familiar ou de amizade), principalmente aquelas que operam no futuro por meio do crédito e aquelas que necessitam de uma cadeia de relações interconectadas (como os empréstimos para financiar a casa própria e os estudos; seguros; planos de saúde etc. $)^{19}$

Os adeptos do modelo econômico criticam o caráter paternalista do modelo solidarista de contrato, por não estar apto a realizar o propósito de proporcionar o bem-estar da coletividade, mas, ao contrário, frequentemente beneficia alguns indivíduos enquanto prejudica outros. Assim, um devedor inadimplente que se beneficia de uma decisão judicial pode estar, na prática, prejudicando indiretamente os demais devedores, porquanto está externalizando os custos para os demais em benefício próprio, o que resulta numa situação socialmente ineficiente.

Significa que a intervenção judicial em favor da parte mais vulnerável de uma relação contratual poderá provocar externalidades negativas, pois pode implicar, indiretamente, no aumento dos custos de transação. ${ }^{20}$

Por fim, as intervenções ex post do Estado podem acarretar comportamentos oportunistas, uma vez que permite à parte mais fraca da relação contratual, na partição do bolo econômico, usufrua do bônus, ao passo que os ônus, a cargo do outro contratante, sejam repassados a outros que não figuravam na relação contratual. ${ }^{21}$

\section{ANÁLISE ECONÔMICA DO DIREITO E OS DISTRATOS NO MERCADO IMOBILIÁRIO}

A Análise Econômica do Direito Contratual abordada no tópico anterior serve perfeitamente como instrumento para tecer algumas reflexões críticas acerca dos

Ibid., p. 203.

Ibid., p. 205.

Ibid., p. 206. 
distratos e o entendimento jurisprudencial do STJ firmado na Súmula $n^{\circ} 543$ de sua jurisprudência.

A imposição do ônus de devolver, à vista, a quase integralidade dos valores pagos pelo (promitente) comprador de uma unidade imobiliária, conforme o que se viu no primeiro tópico, representa um dos principais fatores que impedem a recuperação do mercado imobiliário.

Sob a perspectiva da AED, o entendimento do STJ vem produzindo externalidades negativas aos demais consumidores de unidades imobiliárias, sejam presentes, sejam futuros.

Primeiro porque, pela própria dinâmica da incorporação imobiliária, o financiamento da construção de um empreendimento depende justamente do adimplemento contratual dos diversos adquirentes. Quando um ou mais destes desistem da aquisição, realizando os distratos, não é apenas a incorporadora (que nem sempre é de grande porte) que assume prejuízos deles decorrentes, mas também a coletividade de adquirentes de unidades do mesmo empreendimento.

Em segundo, as incorporadoras, cientes sobre a mudança da dinâmica do mercado imobiliário em decorrência do entendimento jurisprudencial, repassarão os custos de transação e as externalidades aos consumidores futuros de unidades imobiliárias em eventuais novos empreendimentos.

Em exemplo que se aproxima da análise específica dos distratos, Luciano Benetti Timm destaca que

[...] a coletividade em um contrato de financiamento habitacional é representada pela cadeia ou rede de mutuários (e potenciais mutuários), os quais dependem do cumprimento do contrato daquele indivíduo para alimentar o sistema financeiro habitacional, viabilizando novos empréstimos a quem precisa. Assim, se houver quebra na cadeia, com inadimplementos contratuais, o grupo (a coletividade) perderá (ficando sem recursos e terminando por pagar um juro maior). ${ }^{22}$ 
De mais a mais, a adoção da súmula $n^{\circ} 543$ da jurisprudência do STJ pode dar ensejo a comportamentos oportunistas, mormente por parte de consumidoresinvestidores. Num cenário de crise como a que vem ocorrendo no Brasil, não apenas consumidores que perderam o emprego, ou que foram vitimados por problemas de saúde, é que realizam o distrato e vêm se beneficiando do entendimento benéfico do STJ, mas investidores que, em vez de assumir os riscos, como em qualquer investimento, transferiram-nos para as incorporadoras.

\section{CONCLUSÃO}

Desde o início do ano de 2017 há notícias de que o Governo Federal pretende editar uma Medida Provisória para regular os distratos, com o fim de incentivar a recuperação do mercado imobiliário. ${ }^{23}$

Em matéria jornalística publicada no site "Infomoney" no dia 16 de janeiro de 2018, noticia-se que a Medida Provisória será editada em breve, prevendo, em linhas gerais, que a incorporadora teria o direito de reter $50 \%$ do valor pago pelo consumidor inadimplente que deixar de pagar mais de 6 parcelas, ou $30 \%$ quando houver atraso de 3 a 6 prestações. A MP também preveria prazos para a devolução do dinheiro ao consumidor. ${ }^{24}$

De toda forma, tem-se como alvissareira a edição de uma Medida Provisória com semelhante teor ao que foi noticiado, de forma a imprimir maior segurança jurídica aos contratos de (promessa) de compra e venda de imóveis na planta, bem como maior equilíbrio entre os legítimos interesses tanto dos consumidores - sobretudo os, de fato, vulneráveis - quanto às incorporadoras e construtoras que atuam no mercado imobiliário.

\footnotetext{
23 ALVES, Murilo Rodrigues. Medida Provisória dos dos distratos prevê regras para inadimplentes. Disponível em: <. (Acesso em 16/01/2018).

$24 \quad Z O G B I$, Paula. "Única esperança" da construção civil, MP dos distratos ainda gera controvérsia. Disponível em: <>. Acesso em 16/01/2018.
} 
À guisa de uma conclusão, tem-se por oportuno mencionar as brilhantes conclusões de Luciano Benetti Timm sobre a AED aplicada aos contratos em geral, que se encaixam perfeitamente aos casos específicos dos distratos:

(...) seguindo-se nesta linha de raciocínio de um paradigma econômico de contrato, o que o direito contratual pode oferecer ao mercado e qual é a sua função social - e com base na qual se poderia interpretar economicamente 0 artigo 421 do Código Civil?

a) oferecer um marco regulatório previsível e passível de proteção jurídica;

b) minimizar problemas de comunicação entre as partes;

c) salvaguardar os ativos de cada um dos agentes;

d) criar proteção contra o comportamento oportunista;

e) gerar mecanismos de ressarcimento e de alocação de risco;

f) facilitar a interação com o direito antitruste, a regulação do mercado acionário, com a proteção ambiental e ao consumidor em casos específicos.

Em síntese, o direito contratual dentro do modelo econômico de contrato confere segurança e previsibilidade às operações econômicas e sociais, protegendo as expectativas dos agentes econômicos - o que corresponde a um importante papel institucional e social. O sistema tributário (e o direito público como um todo) providenciará a distribuição da riqueza. ${ }^{25}$

Destarte, a real e necessária pacificação da questão dos distratos no mercado imobiliário deve partir do (re)equilíbrio dos riscos e direitos contratuais, não só tendo em vista os (imprescindíveis) direitos dos consumidores, como também os direitos de outros agentes econômicos envolvidos nas relações contratuais (construtoras e incorporadoras), bem assim da coletividade dos consumidores, que, de acordo com a Análise Econômica do Direito, sofre influência das externalidades (positivas ou negativas) decorrentes da boa ou má situação do mercado imobiliário.

\section{REFERÊNCIAS}

AGOSTINI, Renata. Pdg tem novo prejuízo bilionário e caminha para recuperação judicial. Disponível em: <>. Acesso em 16/01/2018

ALVES, Murilo Rodrigues. Medida Provisória dos dos distratos prevê regras para inadimplentes. Disponível em: <>. Acesso em 16/01/2018.

BORGES, Alexandre Walmott et al. A violação à ordem econômica na constituição de 1988 e à lei antitruste no exercício disfuncional da ação na defesa da propriedade intelectual. Revista Jurídica, [S.I.], v. 2, n. 47, p. 335-362, jul. 2017. 
ISSN

2316-753X.

Disponível

em:

<http://revista.unicuritiba.edu.br/index.php/RevJur/article/view/2038/1317>. Acesso em: 25 abr. 2020. doi:http://dx.doi.org/10.21902/revistajur.2316-753X.v2i47.2038.

FIGUEIREDO, Eduardo Fin; GIBRAN, Sandro Mansur. A análise econômica do contrato e as implicações do princípio da função social do contrato no comércio internacional. Percurso, [S.I.], v. 2, n. 19, p. 37, fev. 2017. ISSN 2316-7521. Disponível

em: $<$ http://revista.unicuritiba.edu.br/index.php/percurso/article/view/14/1145>. Acesso em: 25 abr. 2020.

GARCIA, Alexandre. Metade dos imóveis vendidos volta à construtora devido aos distratos. Disponível em: <>. Acesso em 16/01/2018.

GUARAGNI, Fabio André; MIRANDA GONÇALVES, Rubén; RODRIGUES DA SILVA, Douglas. As investigações internas e a análise econômica do direito. Relações Internacionais no Mundo Atual, [S.I.], v. 2, n. 27, p. 1 - 20', abr. 2020. ISSN 2316-2880. Disponível em: <http://revista.unicuritiba.edu.br/index.php/RIMA/article/view/3988/371372310>. Acesso em: 25 abr. 2020. doi:http://dx.doi.org/10.21902/Revrima.v2i27.3988.

MARQUES, Cláudia Lima. Contratos no Código de Defesa do Consumidor: o novo regime das relações contratuais. $8^{a}$ ed São Paulo: Editora Revista dos Tribunais, 2016.

OLIVEIRA, Marcella Gomes de; OPUSZKA, Paulo Ricardo. Direito e atividade econômica - uma análise interdisciplinar sobre a intervenção estatal. Revista Jurídica, [S.I.], v. 2, n. 35, p. 445-463, nov. 2014. ISSN 2316-753X. Disponível em: $<$ http://revista.unicuritiba.edu.br/index.php/RevJur/article/view/968/666>. Acesso em: 25 abr. 2020. doi:http://dx.doi.org/10.21902/revistajur.2316-753X.v2i35.968.

RIBEIRO, Márcia Carla Pereira; AGUSTINHO, Eduardo Oliveira. Economia institucional e nova economia institucional. In: RIBEIRO, Marcia Carla Pereira; KLEIN, Vinicius (Org). O que é análise econômica do direito: uma introdução. Belo Horizonte: Fórum, 2016.

RIZZARDO, Arnaldo. Condomínio Edilício e Incorporação Imobiliária. 5a ed. Rio de Janeiro: Forense, 2017.

STOLTE, Antonio Joélcio; JUNIOR, José Julberto Meira; FARIA, Vinícius Luiz de Oliveira. Breves considerações sobre a análise econômica do direito aplicada na resolução consensual de conflitos. Percurso, [S.I.], v. 2, n. 21, p. 167 - 172, abr. 2018. ISSN 2316-7521. Disponível em: <http://revista.unicuritiba.edu.br/index.php/percurso/article/view/2610/371371401>.

Acesso em: 25 abr. 2020.

TARTUCE, Flávio. Direito Civil. v. 3: Teoria Geral dos Contratos e Contratos em Espécie. $11^{\mathrm{a}}$ ed. Rio de Janeiro: Editora Forense, 2016. 
TIMM, Luciano Benetti. Direito Contratual Brasileiro: Críticas e Alternativas ao Solidarismo Jurídico. $2^{\mathrm{a}}$ ed. São Paulo: Editora Atlas, 2015.

ZOGBI, Paula. "Única esperança" da construção civil, MP dos distratos ainda gera controvérsia. Disponível em: <>. Acesso em 16/01/2018 